\title{
Can theoretical intervention improve hand hygiene behavior among nurses?
}

This article was published in the following Dove Press journal:

Psychology Research and Behavior Management

16 June 2016

Number of times this article has been viewed

\section{Rahim Baghaei' \\ Elham Sharifian' \\ Aziz Kamran ${ }^{2}$}

'Inpatient Safety Research Center, Nursing and Midwifery School, Urmia University of Medical Sciences, Urmia, ${ }^{2}$ Public Health Department, Khalkhal Faculty of Medical Sciences, Ardabil University of Medical Sciences, Ardabil, Iran
Correspondence: Aziz Kamran Public Health Department, Khalkhal Faculty of Medical Sciences, Ardabil University of Medical Sciences, Daneshgah Street, Ardabil Complex University, Ardabil, Iran Tel: 09141599416

Email a.kamran@arums.ac.ir
Background: Hand washing is the best strategy to prevent known nosocomial infections but the nurses' hand hygiene is estimated to be poor in Iran.

Objective: This study aimed to determine the effectiveness of BASNEF (Behavior, Attitude, Subjective Norms, and Enabling Factors) model on hand hygiene adherence education.

Methods: This controlled quasi-experimental study was conducted on 70 hemodialysis unit nurses ( 35 case and 35 control) in the health and educational centers of the University of Medical Sciences of Urmia, Iran. To collect the data, a six-part validated and reliable questionnaire was used. The data were analyzed using SPSS version18, using Wilcoxon, Mann-Whitney, chi-square, and Fisher's exact tests. The significance level was considered $P<0.05$.

Results: The mean age was $38.4 \pm 8.1$ years for the intervention group and $40.2 \pm 8.0$ years for the control group. There was no significant difference between the two groups for any demographic variables. Also, before the intervention, there was no significant difference between the two groups for any components of the BASNEF model. Post-intervention, the attitude, subjective norms, enabling factors, and intention improved significantly in the intervention group $(P<0.001)$, but hand hygiene behavior did not show any significant change in the intervention group $(P=0.16)$.

Conclusion: Despite the improving attitudes and intention, the intervention had no significant effect on hand hygiene behavior among the studied nurses.

Keywords: hand hygiene, adherence, education nurse, behavior

\section{Introduction}

Nosocomial infection is one of the common problems in intensive care units, ${ }^{1}$ and hospital staff hand hygiene behavior is the most important factor in the transmission of nosocomial pathogens. ${ }^{2}$ The impact of health care-associated infection implies prolonged hospital stay, long-term disability, increased resistance of microorganisms to antimicrobials, massive additional financial burden, high costs for patients and their families, and excess deaths, ${ }^{3}$ and hand washing is the easiest and oldest strategy to prevent known nosocomial infections. ${ }^{4}$

The importance of hand hygiene has prompted many researchers to conduct studies. These studies demonstrate the reality that despite its simplicity, low cost, and ease of hand hygiene, the conduct of caregivers is less than expected. ${ }^{5}$ The results of researches conducted in the public sector, even in developed countries, also showed poor performance of nurses and other health workers in hand hygiene. ${ }^{5,6}$

In Iran, overall compliance was 6.4\% (teaching hospital: 7.4\%, public hospital: $6.2 \%$, private hospital: $1.4 \%)$. Nurses $(8.4 \%)$ had the highest rates of compliance. ${ }^{7}$ 
In another Iranian study, the overall compliance with hand hygiene activities was 47.9\% (438 episodes out of 913 potential opportunities) and with sole emphasis on hand washing, the compliance was only $8.5 \%{ }^{8}$ The overall patient nosocomial infection (NI) rate was 3.34 per 100 patients, and the infection rate per 1,000 patient-days was 5.27. ${ }^{9}$

Poor hand hygiene compliance among the Iranian nurses necessitates urgent interventions to improve both hospital infrastructure and staff knowledge. Hence, considering the importance and role of hand hygiene in the health of patients and care providers, interventions should be implemented for health care personnel and all hospital staff to reemphasize the importance of adherence to hand hygiene protocols. Although most health centers run many programs to provide training on this hand hygiene behavior, its acceptance by the employees is low. ${ }^{10}$ The most important means of designing programs for behavior change is to understand the reason behind people's practice and understand what causes the behavior change. ${ }^{11}$ Hence, identifying the reasons for low hand hygiene is necessary for improvement of this behavior. Nurses cite various reasons for washing their hands less frequently, such as the lack of habit, lack of awareness, negligence, routine work, lack of washing and drying equipment, crowded wards, inadequate washing material, defect in the management system, age of service providers, ${ }^{12}$ sex, ${ }^{13}$ knowledge, ${ }^{14}$ attitude, ${ }^{15,16}$ perceived social pressure, ${ }^{17}$ behavioral intention, ${ }^{18}$ and enabling factors. ${ }^{19}$

The understanding and application of behavior change theories may result in an effective program to improve awareness and raise intention, and thus may increase the potential for success of hand hygiene promotion programs. ${ }^{20}$

Health behavior models have provided the basis for the improvement of hand hygiene. Researchers have used health behavior change models as a means to better understand hand hygiene behavior, and one of the most popular models is the theory of planned behavior (TPB). TPB postulates that behavior is most directly predicted by intention, which in turn is predicted by attitudes, subjective norms, and perceived behavioral control. However, in this model, enabling factor is neglected, which according to Fuentes-Gómez et $\mathrm{al}^{21}$ is one of the most important factors of hand hygiene in hospitals. $\mathrm{O}^{\prime}$ Boyle et $\mathrm{al}^{22}$ showed that intensity of activity in the nursing unit, rather than TPB variables, predicted observed adherence to hand hygiene.

Thus, according to the studies presented and the factors influencing hand hygiene adherence behavior, it seems that BASNEF (the Behavior, Attitude, Subjective Norms, and
Enabling Factors) model is an adequate framework for this study. The model includes components of attitude, behavior, subjective norms, and enabling factors. In this model, the attitudes are combined with subjective norms and affect behavioral intention. The theory says that behavior generally occurs following the intention which is influenced by attitudes that exist toward behavior. ${ }^{23}$

BASNEF is a comprehensive model which is designed to study behaviors and plans to change them and to define the factors effective on individuals' decision making. Based on this model, individuals develop a new behavior when they believe it is beneficial for them. ${ }^{24}$

This study aimed to determine the effectiveness of BASNEF model on hand hygiene adherence education.

\section{Methods}

This controlled quasi-experimental study was conducted on hemodialysis unit nurses in health and educational centers of Urmia University of Medical Sciences, Iran. The intervention group participants were nurses in the hemodialysis unit of Taleghani Hospital, Iran, and the control group participants were nurses in the hemodialysis unit of Imam Khomeini Hospital, Iran. The requirement for informed consent and ethical approval was waived by the Medical Ethics Committee of Urmia University of Medical Sciences. The inclusion criteria were the desire to participate in the study and employment in the hemodialysis units of the health and training centers of University of Medical Sciences of Urmia. According to the data in a similar article, ${ }^{25}$ the sample size was determined as 35 for each group; hence, a total of 70 individuals were included in the study. To collect data, a six-part questionnaire was used as following:

1. The demographic questionnaire included 12 items such as age, sex, recruitment type, and duration.

2. BASNEF model-based questionnaire was designed due to the lack of access to a standard questionnaire related to hand hygiene adherence by nurses with structures of BASNEF model, and the designed tools were tested during the pilot study. In the questionnaire designed by the researcher, based on previous researches and the literature related to any of the matters under investigation, 45 questions were posed by the research team including 14 attitude items based on Likert scale after confirming the validity and reliability of items. The respondent expressed his/her views on different levels, including strongly agree, agree, neutral, disagree, or strongly 
disagree, and for each answer, a score was considered in the range of $1-5$. In scoring Likert scale, both positive and negative questions were taken into account. The keys to questions were prepared accordingly, ie, if a sentence was positive, the highest score was given to strongly agree, otherwise the highest score was given to strongly disagree. The scores ranged from 14 to 70 .

3. The subjective norm questionnaire consisted of nine questions based on the Likert scale: strongly agree, agree, neutral, disagree, or strongly disagree. The answers scored 1-5, showing different values for each statement. The personnel chose each alternative due to its impact as a subjective norm (nursing colleagues, the director of nursing, the chief executive of the hospital, the patients). The scores ranged from 9 to 45 .

4. Enabling factors included seven questions designed based on the Likert scale and the scores ranged from 7 to 35 .

5. Behavior intention included seven questions with two options: Yes or No. A score of 1 was assigned to Yes and 0 to No.

6. Performance or behavior included eight items concerning the acceptance of washing hands before and after the training (performance) program, which was determined by observation.

To determine the content validity of the questionnaire, a quantitative method was used, which included the determination of content validity ratio and content validity index (CVI). In the CVI determining stage, all the items of questionnaire had acceptable validity and none of them was removed. For all constructs, the CVI was calculated by assessing the average of each construct's items (subjective norms 0.95 , attitude 0.94 , enabling factors 0.98 , behavior 0.96 , and intention to behavior 0.98 ). To confirm the reliability, an internal consistency method was used. The questionnaire was distributed among 20 nurses, similar to the target group, who were working at Emam Khomeini Hospital in Ardabil. The Cronbach's alpha for the enabling factor was 0.82 , for attitude ratio to the behavior 0.916 , for behavior 0.86 , and for subjective norm 0.88. (Questionnaire is available to readers on request.)

Before choosing the participants, required explanations were provided on the objectives of the study, and the confidentiality of the participants was ensured. The staff members were told not to write their names on the questionnaire. Also, they were informed that if they did not want to cooperate at any stage of the research, they were free to discontinue their participation. Before the intervention, the study subjects were provided the required explanations on how to complete the questionnaires and were asked to complete the self-report questionnaire based on the BASNEF model. After the pretest, the nurses were homogenized in two groups according to background variables such as age, education, sex, marital status, income, and type of employment. Then, the sampling was performed using the availability sampling method during the morning and evening shifts. To reduce the possibility of contact between the control and intervention groups, the participants were selected from different hospitals and were assigned to the control and intervention groups. The control group was given no intervention. To improve the participation in the intervention group, the group was divided into three small subgroups of 12 each. After an overall assessment for the nurses, two training intervention sessions (each session consisted of two 1-hour parts, which took a total of 2 hours), were held for the nurses in the hemodialysis ward, based on the components of the BASNEF model.

The overall content of the meetings was prepared in the form of a booklet and compact disc (CD) (including information on basic knowledge of hand hygiene adherence behaviors and BASNEF model) and given to the nurses. After the intervention, the subjects were followed for 2 months; after 2 months, the questionnaires were collected from both the groups. The performance was measured through self-reported hand washing records. After follow-up data collection, the data were analyzed. In order to comply with research ethics, after the end of the treatment, the educational pamphlet was also given to the control group.

The data were analyzed using SPSS version18 (Chicago, IL, USA), descriptive and analytical statistics such as MannWhitney test for comparison of two independent groups, and Wilcoxon test before and after the intervention. Moreover, chi-square test and Fisher's exact test were used to determine the relationship between the qualitative variables. The significance level was considered $P<0.05$.

\section{Results}

The mean age was $38.4 \pm 8.1$ years for the intervention group and $40.2 \pm 8.0$ years for the control group. There was no significant difference between the two groups (intervention and control) regarding age and recruitment duration. Most of the participants in both groups were women. The two groups were matched in sex and educational level. Demographic characteristics of the participants are presented in Table 1.

Before the intervention, there was no significant difference between the two groups (intervention and control) 
Table I Comparison of demographic characteristics between intervention and control groups in terms of sex

\begin{tabular}{|c|c|c|c|c|}
\hline \multirow[t]{2}{*}{ Variables } & \multicolumn{2}{|c|}{ Control } & \multicolumn{2}{|c|}{ Intervention } \\
\hline & No & $\%$ & No & $\%$ \\
\hline \multicolumn{5}{|l|}{ Sex } \\
\hline Male & 8 & 22.9 & 5 & I4.3 \\
\hline Female & 27 & 77.1 & 30 & 85.7 \\
\hline Total & 35 & 100 & 35 & 100 \\
\hline$P$-value (chi-square test) & \multicolumn{4}{|c|}{$P=0.35$} \\
\hline \multicolumn{5}{|l|}{ Educational level } \\
\hline Technician and lower & 3 & 8.6 & 4 & $\mathrm{II} .4$ \\
\hline Bachelors & 32 & 91.4 & 31 & 88.6 \\
\hline Total & 35 & 100 & 35 & 100 \\
\hline$P$-value (Fisher's exact test) & \multicolumn{4}{|c|}{$P=0.7$} \\
\hline \multicolumn{5}{|l|}{ Recruitment type } \\
\hline Official & 23 & 65.7 & 7 & 48.6 \\
\hline Contractual & 7 & 20.0 & 7 & 20.0 \\
\hline Project: contract & 5 & 14.3 & II & 31.4 \\
\hline Total & 35 & 100 & 35 & 100 \\
\hline$P$-value (chi-square test) & \multicolumn{4}{|c|}{$P=0.20$} \\
\hline \multicolumn{5}{|l|}{ Recruitment duration } \\
\hline$<5$ years & 3 & 8.6 & 5 & 14.3 \\
\hline $5-10$ years & 9 & 25.7 & 12 & 34.3 \\
\hline $10-15$ years & 9 & 25.7 & 5 & 14.3 \\
\hline 15 years and more & 4 & 40.0 & 13 & 37.1 \\
\hline Total & 35 & 100 & 35 & 100 \\
\hline$P$-value (Fisher's exact test) & \multicolumn{4}{|c|}{$P=0.55$} \\
\hline
\end{tabular}

regarding the components of the BASNEF model. After the intervention, the values of the mentioned variables increased significantly in the case group and showed a significant difference compared to the control group $(P<0.001)$.

Table 2 shows the median and standard deviation as well as the median differences of the components of the BASNEF model in the two groups before and after intervention. After intervention, attitude increased significantly in the case group compared to control group $(P<0.001)$. Similar results were obtained with regard to the enabling factors $(P<0.001)$.

Table 3 compares the median values of subjective norms, intention, and behavior before and after intervention in the two groups (intervention and control). After intervention, subjective norms $(P<0.001)$ and intention $(P<0.001)$ increased significantly in the case group compared to the control group $(P<0.001)$, but the findings did not show any significant improvement in hand hygiene (behavior) in the case group $(P=0.16)$ and significant changes during time was not seen in the control group.

\section{Discussion}

Although it is well accepted that hand hygiene is the most important behavior for reducing health care-associated infections, hand hygiene compliance is often low. The results of the present study did not show a statistically significant improvement in hand hygiene, and this finding is consistent with that reported by two major systematic reviews on the impact of interventions on hand hygiene compliance. These reviews include a 2010 Cochrane systematic review, which found insufficient evidence that hand hygiene interventions improve hand hygiene in the hospital setting, ${ }^{26} \mathrm{http}$ ://www. ncbi.nlm.nih.gov/books/NBK133371/ and a 2008 systematic review, which addressed studies evaluating hand hygiene interventions and health care-associated infections in acute and long-term care settings. ${ }^{27}$

Hence, we can say that high-quality evidence demonstrating the type of interventions that are most effective is lacking. Hand hygiene among health care staff is a challenge, and evidences show that despite the convenience and low cost, hand hygiene adherence behavior is less than expected among health care providers. ${ }^{8}$ Despite the presence of theorybased studies, which have been successful in improving hand hygiene behaviors, there are also some studies that have failed to achieve any change. ${ }^{28}$ Another study, which has a conclusion in line to our findings, concluded that hand hygiene interventions that target changes in attitudes, intentions, or self-reported practice are likely to fail in terms of changing behavior. ${ }^{29}$

The results of the present study showed that the mean score of BASNEF model constructs, which include attitude,

Table 2 Comparison of the median upper quartile (UQ) of attitude and enabling factors in the intervention and control groups before and after the intervention

\begin{tabular}{llll}
\hline Variables & Case & Control & Mann-Whitney test \\
\hline Attitude & & & \\
Before intervention & $37(40)$ & $37(40)$ & $P=0.8 I, Z=-0.23$ \\
After intervention & $44(57)$ & $37(47)$ & $P=0.004, Z=-2.8$ \\
Wilcoxon test & $P<0.00 \mathrm{I}, Z=-4.2$ & $P=0.43, Z=-0.78$ & \\
Enabling factors & & $16(23)$ & \\
Before intervention & $18(23)$ & $18(23)$ & $P=0.82, Z=-0.22$ \\
After intervention & $20(24)$ & $P=0.47, Z=-0.7 \mathrm{I}$ & $P=0.1 \mathrm{I}, Z=-1.5$ \\
Wilcoxon test & $P<0.00 \mathrm{I}, Z=-3.6$ & & \\
\hline
\end{tabular}


Table 3 Comparison of the median upper quartile (UQ) of subjective norms, intention, and behavior in the intervention and control groups before and after the intervention

\begin{tabular}{llll}
\hline Variables & Case & Control & Mann-Whitney test \\
\hline $\begin{array}{l}\text { Subjective norms } \\
\text { Before intervention }\end{array}$ & $25(28)$ & $25(28)$ & $P=0.6, Z=-0.49$ \\
$\begin{array}{l}\text { After intervention } \\
\text { Wilcoxon test }\end{array}$ & $30(34)$ & $26(29)$ & $P=0.002, Z=-3.1$ \\
$\begin{array}{l}\text { Intention } \\
\text { Before intervention }\end{array}$ & $P<0.00 I, Z=-4.1$ & $P=0.70, Z=-0.37$ & \\
After intervention & $6(7)$ & $7(7)$ & $P=0.006, Z=-2.7$ \\
Wilcoxon test & $7(7)$ & $7(7)$ & $P=0.01, Z=-2.4$ \\
Behavior & $P<0.001, Z=-3.8$ & $P=0.41, Z=-0.8 I$ & \\
$\begin{array}{l}\text { Before intervention } \\
\text { After intervention }\end{array}$ & $22(23)$ & $22(23)$ & $P=0.89, Z=-0.12$ \\
Wilcoxon test & $23(23)$ & $22(23)$ & $P=0.28, Z=-1.06$ \\
\hline
\end{tabular}

enabling factors, subjective norms, and intention to behavior, increased significantly. Also, based on the BASNEF model, the results showed that educational intervention was not successful in improving hand hygiene adherence behaviors of the nurses. This finding is in line with that of Bikmorady et al, ${ }^{30}$ who also did not record a significant improvement in hand hygiene of the participants with soap and water after the trainings. Many texts claim that adherence improvement is temporary after educational interventions. ${ }^{31,32}$ In a study by Huang et al, ${ }^{33} 4$ months post-education, hand hygiene compliance significantly improved $(P<0.001)$ for the nurses in the experimental group compared to the control group. In contrast, Gould et $\mathrm{al}^{34}$ found that 3 months after the education intervention, the number of essential hand hygiene episodes performed was similar in the intervention and control groups.

Lack of improvement of the hand hygiene adherence in this study is in fact due to the conditions prevailing in the country's hospitals since the studies show that despite repeated training programs in hospitals, hand hygiene adherence is not as desired in hospital wards. A study by Ravaghi et $\mathrm{al}^{35}$ showed that although all nurses were educated on hand hygiene, they did not have an adequate knowledge of the standards and principles of desired behavior. However, in a study by Hosseinialhashemi et al, ${ }^{36}$ participants appeared to have sufficient knowledge and proper attitudes regarding hand hygiene, but compliance practices were suboptimal. Also, in a study by Askarian et al, ${ }^{37}$ the results indicated negligence in various aspects of infection control. In order to design more reliable interventions, there is a need to have more information on the determinants of these behaviors because in most cases, though having adequate knowledge and positive attitudes, health staff do not observe it.
Although this study has been unable to provide clear evidence of the effect of intervention to promote hand hygiene behavior, the findings should not be taken to suggest that attempts to promote hand hygiene compliance are not worth undertaking. Soundly designed studies are still required to evaluate the effectiveness of interventions intended to improve hand hygiene compliance.

\section{Conclusion}

Despite the improving attitudes and intention, the intervention had no significant effect on hand hygiene behavior among the studied nurses.

\section{Study limitations}

A limitation of the study was the relatively small sample size. For this reason, these findings cannot be generalized to other nursing communities based on this study alone. The data collection process before and after the intervention was based on self-recording by hospital staff, which is another limitation of the present study.

\section{Disclosure}

The authors report no conflicts of interest in this work.

\section{References}

1. Naidu K, Nabose I, Ram S, Viney K, Graham S, Bissell K. A descriptive study of nosocomial infections in an adult intensive care unit in Fiji: 2011-12. J Trop Med. 2014;2014:545160.

2. Kampf G, Löffler H, Gastmeier P. Hand hygiene for the prevention of nosocomial infections. Dtsch Arztebl Int. 2009;106(40): 649-655.

3. WHO Guidelines on Hand Hygiene in Health Care. First global patient safety challenge: clean care is safer care. Avaliable from: http://www. ncbi.nlm.nih.gov/books/NBK144013/. accessed March 18,2016.

4. Pittet D. Improving compliance with hand hygiene in hospitals. Infect Control Hosp Epidemiol. 2000;21(6):381-386. 
5. Akyol A. Hand hygiene among nurses in turkey: opinions and practices. J Clin Nurs. 2007;16(3):431-437.

6. Venkatesh A, Lankford M, Rooney D, Blachford T, Watts C, Noskin G. Use of electronic alerts to enhance hand hygiene compliance and decrease transmission of vancomycin-resistant. Am J Infect Control. 2008;36(3):199-205.

7. Ataei B, Zahraei SM, Pezeshki Z, et al. Baseline evaluation of hand hygiene compliance in three major hospitals, Isfahan, Iran. $J$ Hosp Infect. 2013;85(1):69-72.

8. Naderi HR, Sheybani F, Mostafavi I, Khosravi N. Compliance with hand hygiene and glove change in a general hospital, Mashhad, Iran: an observational study. Am J Infect Control. 2012;40(6):e221-e223.

9. Pourakbari B, Rezaizadeh G, Mahmoudi S, Mamishi S. Epidemiology of nosocomial infections in pediatric patients in an Iranian referral hospital. J Prev Med Hyg. 2012;53(4):204-206.

10. Tibballs J. Teaching hospital medical staff to hand wash. Med J Aust. 1996;164(7):395-398.

11. Whitby M, McLaws ML, Ross MW. Why healthcare workers don't wash their hands: a behavioural explanation. Infect Control Hosp Epidemiol. 2006;27:484-492.

12. Tai JW, Mok ESB, Ching PT, Seto WH, Pittet D. Nurses and physicians' perceptions of the importance and impact of healthcare-associated infection and hand hygiene: a multi-center exploratory study in Hong Kong. Infect Control Hosp Epidemiol. 2009;37(4):320-333.

13. Amerion A, Tavakoli R, Sanaeinasab H, Karimizarchi A. Knowledge of hospital infection control by supervisors in three selected military hospitals in Islamic Repoblic of Iran. Eur J Sci Res. 2010;5:66.

14. Malekmakan L, Haghpanah S, Askarian M, Jowkari M, Moalaee M. Hand hygiene in Iranian health care workers. Am J Infect Control. 2008;36(8):602-603.

15. Quiros D, Lin S, Larson E. Attitudes toward practice guidelines among intensive care unit personnel: a cross-sectional anonymous survey. Heart Lung. 2007;36(4):287-297.

16. Snow M, White GLJ, Alder SC, Stanford JB. Mentor's hand hygiene practices influences student's hand hygiene rates. Am J Infect Control. 2006;34(1):18-24.

17. Sax H, Uckay I, Richet H, Allegranzi B, Pittet D. Determinants of good adherence to hand hygiene among healthcare workers who have extensive exposure to hand hygiene campaigns. Infect Control Hosp Epidemiol. 2007;28(11):1267-1274.

18. Pittet D, Simon A, Hugonnet S, Pessoa-Silva CL, Sauvan V, Perneger TV. Hand hygiene and physicians: performance, beliefs, and perceptions. Ann Intern Med. 2004;141:1-8.

19. Erasmus V, Brouwer W, van Beck EF, Oenema A, Daha TJ, Richardus JH. A qualitative exploration of reasons for poor hand hygiene among hospital workers: lack of positive role models and of convincing evidence that hand hygiene prevents cross-infection. Infect Control Hosp Epidemiol. 2009;31(3):283-294.

20. Al-Tawfiq JA, Pittet D. Improving hand hygiene compliance in healthcare settings using behavior change theories: reflections. Teach Learn Med. 2013;25(4):374-382.

21. Fuentes-Gómez V, Crespillo-García E, Enríquez de Luna-Rodríguez M, et al. Factors predisposing, enabling and reinforcing hand hygiene in hospitals. Rev Calid Asist. 2012;27(4):197-203.
22. O'Boyle CA, Henly SJ, Larson E. Understanding adherence to hand hygiene recommendations: the theory of planned behavior. Am J Infect Control. 2001;29(6):352-360.

23. Didarloo A, Shojaeezadeh D. Health Promotion Planning. 1st ed. Tehran: Sobhan; 2009.

24. Sarayloo K, Moghadam ZB, Mansoure JM, Mostafa H, Mohsen S. The impact of an educational program based on BASNEF model on the selection of a contraceptive method in women. Iran J Nurs Midwifery Res. 2015;20(2):171-178.

25. McGuckin N, Taylor A, Martin V, Porten L, Salcido R. Evaluation of a patient education model for increasing hand hygiene compliance in an inpatient rehabilitation unit. Am J Infect Control. 2004;332(4):234-238.

26. Gould DJ, Moralejo D, Drey N, Chudleigh JH. Interventions to improve hand hygiene compliance in patient care. Cochrane Database Syst Rev. 2010;(9):CD005186.

27. Backman C, Zoutman DE, Marck PB. An integrative review of the current evidence on the relationship between hand hygiene interventions and the incidence of health care-associated infections. Am J Infect Control. 2008;36(5):333-348.

28. Reason FP. Improving Hand Hygiene Compliance. Simon Fraser University; Burnaby, Ca; 2008.

29. Jenner EA, Fletcher BC, Watson P, Jones FA, Miller L, Scott GM. Discrepancy between self-reported and observed hand hygiene behaviour in healthcare professionals. J Hosp Infect. 2006;63(4):418-422.

30. Bikmorady A, Mardani D, Soltanian A, Khatiban M. The impact of educational evidence-based hand washing program on knowledge, attitude, and adherence of intensive care units nurses. J Hamadan Nurs Mid Facult. 2013;21(3):5-13.

31. Lam B, Lee J, Lau Y. Hand hygiene practices in a neonatal intensive care unit: a multimodal intervention and impact on nosocomial infection. Pediatrics. 2004;114(5):e565-e571.

32. Colombo C, Giger H, Grote J, Deplazes C, Pletscher W, Luthi R. Impact of teaching interventions on nurse compliance with hand disinfection. $J$ Hosp Infect. 2002;51(1):69-72.

33. Huang SS, Yokoe DS, Hinirichsen VL, et al. Impact of routine intensive care unit surveillance cultures and resultant barrier precautions on hospital-wide methicillin-resistant Staphylococcus aureus bacteremia. Clin Infect Dis. 2006;43:971-978.

34. Gould DJ, Moralejo D, Drey NS, Chudleigh J. Measuring hand washing performance in health service audits and research studies. $J$ Hosp Infect. 2007;66:109-115.

35. Ravaghi H, Abdi Z, Heyrani A. Hand hygiene practice among healthcare workers in intensive care units: a qualitative study. $J$ Hosp. 2015;13(4):41-52.

36. Hosseinialhashemi M, Sadeghipour Kermani F, Palenik CJ, Pourasghari H, Askarian M. Knowledge, attitudes, and practices of health care personnel concerning hand hygiene in Shiraz University of Medical Sciences hospitals, 2013-2014. Am J Infect Control. 2015;pii:S0196-S6553(15)00512-X.

37. Askarian M, Hajiabadi MJ, Kashkooli YA, et al. Improving infection prevention methods in hemodialysis units: a multicenter survey. $\mathrm{Am} J$ Infect Control. 2014;42(2):193-194.
Psychology Research and Behavior Management

\section{Publish your work in this journal}

Psychology Research and Behavior Management is an international, peerreviewed, open access journal focusing on the science of psychology and its application in behavior management to develop improved outcomes in the clinical, educational, sports and business arenas. Specific topics covered include: Neuroscience, memory \& decision making; Behavior

\section{Dovepress}

modification \& management; Clinical applications; Business \& sports performance management; Social and developmental studies; Animal studies. The manuscript management system is completely online and includes a quick and fair peer-review system. Visit http://www.dovepress. com/testimonials.php to read real quotes from published authors. 